\title{
Ennalta määrätyn episteeminen kulttuuri ja politiikan liikkumatila
}

\author{
PAULI HUOTARI \\ TEPPO ESKELINEN
}

Politiikan tutkimuksessa kiinnitetään usein huomiota politiikan liikkumatilaan (policy space). Tällä tarkoitetaan poliittisten yhteisöjen tosiasiallista autonomiaa politiikan sisältöjen määrittelyssä (Akyüz 2007; Kentikelenis ym. 2016). Kysymys on tärkeä erityisesti demokratian kannalta: muodollisten demokraattisten instituutioiden lisäksi tarvitaan aitoa mahdollisuutta muuttaa yhteiskuntaa demokraattisen politiikan keinoin. Politiikan liikkumatilan kaventumisesta on kannettu perusteltua huolta erityisesti vuosituhannen taitteen globalisaatiokirjallisuudessa, jossa katsottiin ylikansallisen talouden sääntelyn johtavan demokraattisen liikkumatilan kaventumiseen (Gill 2002; Schneiderman 2000). Lisäksi asiasta on käyty keskustelua esimerkiksi Euroopan unionin (Föllesdal ja Hix 2006; Reho 2014) ja virkamiesvallan (Eskelinen ja Sorsa 2013; Reddy 1996) konteksteissa.

Viime aikoina keskustelu politiikan liikkumatilasta on laajentunut epistemologiaan. Tieteellisen tiedon ja asiantuntijuuden voi katsoa muodostuneen nykyaikaisessa hallinnoinnissa keskeisiksi oikeuttamisen mekanismeiksi (esim. Ylöstalo 2020), kun oikeuttamisella tarkoitetaan julkisen puheen strategioita politiikkatoimien perustelemiseksi (Abulof ja Kornprobst 2017; Chambers 2010). Nykyaikaiseen hallinnointiin kuuluu voimakkaita epäpolitisoivia piirteitä, ja poliittisia ongelmia esitetäänkin entistä useammin hallinnollisina ongelmina tai ainoastaan optimointiongelmina. Tätä kutsutaan toisinaan pyrkimykseksi "ottaa politiikka (politics) pois politiikasta (policy)" (Hill ja Varone 2021, 4). Politiikan häivyttäminen ja hallinnon vallan korostuminen ovat asiantuntijuutta laajempia ilmiöitä, mutta tieto ja asiantuntijuus toimivat usein tällaisen vallan muodon oikeuttajina ja vahvistajina, erityisesti kun tieto kyetään paketoimaan hallinnolle helposti käsiteltävään muotoon. Tällöin asiantuntijuuden rooliksi muodostuu myös oikeuttaa demokraattisen liikkumatilan kaventamista.

Täydennämme tässä tekstissä keskustelua poliittisesta liikkumatilasta laajentamalla analyysia tiedon roolista. Esitämme, että demokraattisen liikkumatilan rajoituksia tulisi analysoida hallinnollisten rajoitteiden ja tiedolla oikeuttamisen lisäksi myös episteemisten kulttuurien mielessä. Episteemisellä kulttuurilla tarkoitetaan tietämisen tapaa: tapoja tuottaa ja oikeuttaa tietoa. Miten tiedon mahdollisuuksiin, rajoihin ja muotoihin suhtaudutaan? Mihin tiedon ajatellaan perustuvan ja miten sitä luontevimmin sovelletaan? Tällaista tietokäsitystä on syytä käsitellä tiedolla oikeuttamisesta erillisenä ilmiönä, vaikka ne ovatkin osittain päällekkäisiä. Ymmärrys poliittisesta liikkumatilasta jää puuteelliseksi, ellei myös yleisempi tietosuhde kuulu analyysin kohteisiin. Koska ideoilla on tapana muokata politiikkaa (esim. Campbell 2002), episteemisillä kulttuureilla on välittömiä vaikutuksia politiikan tekemisen tapoihin.

Episteemisten kultturien käste on peräisin antropologi Karin Knorr Cetinan (1999) teoksesta Epistemic Cultures, how the sciences make knowledge ${ }^{1}$, ja sitä on sovellettu erityisesti tieteen- ja teknologiantutkimuksen piirissä. Cetina itse on tutkinut episteemisiä kulttuureja mikrotasolla, esimerkiksi tieteenetnograafisesti laboratorioissa. Näissä tutkimuksissa käsitettä 
käytetään mikrososiologisena työkaluna, joskaan Cetina ei pidä episteemisiä kulttuureja tieteenalakohtaisina. Tässä tekstissä esitämme, että käsite on sovellettavissa makronäkökulman ja historiallisen kontekstin tarkastelun työkaluna, siinä missä tiedollisten kulttuurien moninaisuuden tunnistamiseen mikrotasollakin. Politiikan tutkimuksen kannalta olennaista on erityisesti episteemisten kulttuurien risteäminen muun sosiaalisen ja poliittisen elämän kanssa.

\section{ENNALTA MÄÄRÄTYN EPISTEEMINEN KULTTUURI}

Miten sitten nykyisin vallitsevaa, hegemonista tai nousevaa episteemistä kulttuuria voisi kuvata? Aiemmassa tutkimuksessa on havaittu esimerkiksi eri tieteenaloilla vallinneiden episteemisten kulttuurien konvergenssia kohti teknotieteellistä paradigmaa (Kastenhofer 2007). Tämä tarkoittaa esimerkiksi helposti kontrolloitavissa olevien tieteellisten objektien ja sovellettavuuden suosimista ymmärtämisen tavoitteen sijaan. Yhtenäisten episteemisten kulttuurien tasolla kiinnostavinta on kuitenkin tutkia tiedollisten kulttuurien suhdetta tulevaisuuden avoimuuteen. Tämä on myös politiikan liikkumatilan näkökulmasta olennainen kysymys. Esitämmekin, että on tarpeen tunnistaa episteeminen kulttuuri, jota voisi kutsua ennalta määrätyn episteemiseksi kulttuuriksi. Tarkoitamme tällä taipumusta perustaa yhteiskunnallista tiedontuotantoa ja päätöksentekoa tiedolliseen ekstrapolointiin, eli nykyhetkestä taaksepäin kerätyistä viitepisteistä käsin tulevaisuuden estimointiin.

Toki tulevaisuutta on aina jossain määrin pystyttävä ennakoimaan ja demokraattisessa politiikassakin on aina jatkuvuuksia, institutionaalista jäykkyyttä ja polkuriippuvuuksia. Episteemistä kulttuuria on kuitenkin tarpeen tarkastella politiikan liikkumatilaan ja muutoksen mahdollisuuksiin vaikuttavana tekijänä. Ennalta määrätyn episteeminen kulttuuri on syytä määritellä ideaalityyppinä: se muodostuu aposteriorisen tiedonmuodostuksen, ja apriorisen mahdollisuuksien ja toivottavuuksien määrittämisen yhdistelmästä. Tiedon muoto ja tapa jolla se tulee yhteiskuntaan perustuu oletukseen kehityskulkujen ja vaikutussuhteiden jatkuvuudesta. Vaikka todellisuus onkin monimutkaisempi ${ }^{2}$, ideaalityyppinen määritelmä auttaa rajoiltaan epätarkan kulttuurisen tendenssin piirteiden tavoittamisessa.

Alla kehitämme ja perustelemme ennalta määrätyn episteemisen kulttuurin käsitettä politiikan tutkimuksen mahdollisena tutkimuskohteena. Pyrimme osoittamaan, miten tämä episteeminen kulttuuri toimii, ja esittämään, miksi (ideaalityyppinen) episteeminen kulttuuri on hyödyllinen tutkimuskohde ja analyysin työkalu. Näin (ideaalityyppisen) ennalta määrätyn episteemisen kulttuurin analysointi auttaa myös ymmärtämään demokratian liikkumatilan tietokäsityksiin liittyviä rajoitteita. Ilmiön tunnistamisen ja yleisen nimeämisen lisäksi on syytä kiinnittää huomiota sen yleisyyteen ja ilmenemismuotoihin.

Tiedolliseen ekstrapolointiin sisältyy kahdenlaisia politiikan tilaa kaventavia piirteitä. Ensinnäkin se aiheuttaa yleistä konservatiivisuutta: asioiden oletetaan jatkuvan pääsääntöisesti ennallaan, eikä yhteiskunnallisia katkoksia pystytä tällöin ennakoimaan tai tuottamaan. Toiseksi tiedollisella ekstrapoloinnilla on taipumus tuottaa itseään uusintavia asiantiloja, koska oletus yhteiskunnallisen tapahtuman väistämättömyydestä lisää myös sen tapahtumisen todennäköisyyttä. Seuraavaksi hahmottelemme ennalta määrätyn episteemisen kulttuurin dominanssin seurauksia muutamien erilaisten esimerkkien kautta. Esimerkkien jälkeen palaamme 
pohtimaan ennalta määrätyn episteemisen kulttuurin luonnetta ja asemaa nykyisessä historiallisessa hetkessä, ja hahmottelemaan demokraattista tilaa avaavaa episteemistä kulttuuria ja politiikan tutkimuksen roolia tällaisen kulttuurin tuottamisessa.

\section{ESIMERKKEJÄ: KEINOÄLY JA NÄYTTÖPOHJAINEN POLITIIKKA}

Käsittelemme seuraavaksi kahta tapausta, joissa tiedon muodon ja sen soveltamisen voi katsoa uusintavan mennyttä: keinoälyä ja näyttöpohjaista politiikkaa. Nämä esimerkit on tarkoituksella valittu niin, että niiden yhteiskunnallis-sosiaaliset kontekstit ovat erilaisia. Molemmat kuitenkin kuvaavat sekä ennalta määrätyn episteemisen kulttuurin ilmenemistapaa että sen laajaa vaikutuspiiriä.

Keinoäly tarjoaa useita hyviä esimerkkejä ennalta määrätyn episteemisestä kulttuurista. Teknologia ei ole moraalisessa mielessä neutraalia (Cooley 1995) ja viime aikoina keinoäly on herättänyt pohdintaa teknologian eettisistä ja poliittisista seurauksista (Zajko 2021). Algoritminen päätöksenteko omaksuu ja toistaa olemassa olevia yhteiskunnallisia vinoumia: "objektiivisen arvostelukyvyn lupauksen varaan luodut järjestelmät päätyvät uusintamaan vinoumia ja eriarvoisuuksia, joita niiden 'kouluttamiseen' käytetyt yhteiskunnat sisältävät” (emt.). ${ }^{3}$

Käsitykset relevantista tiedosta heijastavat aina myös kulttuurisia ennakkoluuloja (Fricker 2007), ja tekoälyn tueksi on tuotettava ymmärrystä relevanssista. Politiikan tutkimuksen professori Michael Sandelin mukaan keinoäly antaa vallitsevien vinoumien toistamiselle ikään kuin tieteellistä uskottavuutta. Menneisyyden syrjivät ja vapautta rajoittavat elementit näyttäytyvät objektiivisina ja neutraaleina (Pazzanese 2020). Jos tiedon käyttöön ei sisälly perustavanlaatuisen uudelleenarvioinnin mahdollisuutta, kyse on ennalta määrätyn episteemisestä kulttuurista. Merkitseehän olennainen kulttuuris-poliittinen muutos aina myös episteemistä muutosta, eikä vain arvojen muutosta.

Mike Zajkon (2021) mukaan perinteiset lähestymistavat laskennallisissa tietojenkäsittelytieteissä vahvistavat vallitsevia valtasuhteita ja asiantiloja. Vallitsevat asiantilat eivät aina ole ongelmallisia, mutta niiden säilyttämiseen taipuvainen episteeminen kulttuuri rajoittaa yhteiskunnallista liikkumatilaa. Keinoälyn kehitystyö saattaa noudatella vallitsevien järjestelmien logiikkaa, esimerkiksi makrotason kapitalistista logiikkaa. Toisaalta keinoälyn kehittäjien sosioekonomisella taustalla on myös vaikutuksensa lopputulokseen. Seurauksena keinoäly saattaa esimerkiksi uusintaa kielessä eläviä sukupuoleen liittyviä oletuksia tai päätellä henkilön sukupuolen ammatin perusteella.

Käytännön esimerkkejä keinoälyn konservatiivisesta soveltamisesta on paljon. Viime aikoina on kehitetty tunteiden kanssa vuorovaikuttavaa keinoälyä (emotional $A I$ ), jota hyödynnetään työntekijöiden palkkaamisessa. Tunnekeinoälyn käytön rationaliteetti palkkauspäätöksissä perustuu siihen, että tehtäviin pystytään palkkaamaan mahdollisimman sopivia henkilöitä. Samalla ihmisten taipumuksiin suhtaudutaan ikään kuin ne olisivat muuttumattomia ja esimerkiksi halut kehittyä johonkin toiseen suuntaan nykyisestä jäävät toisarvoisiksi. Dystooppisempana esimerkkinä voidaan nostaa Yhdysvaltojen Pascossa paikallisen poliisin kehittämä algoritmi, joka pisteyttää kansalaisia heidän "rikosalttiutensa" perusteella. Alttius rikosten tekemiseen määritellään esimerkiksi rikoshistorian ja poliisin analyytikoiden mielivaltaisten päätösten 
perusteella. Rikosalttiuden päättely henkilön rikoshistoriasta ja poliisin reagointi ikään kuin kehityskulku vanhoista rikoksista uusiin rikoksiin olisi väistämätön, kuvaa ennalta määrätyn episteemisen kulttuurin hyvin raadollista ilmenemismuotoa. Algoritmin käytön myötä poliisi on saattanut häiritä ihmisiä, vaikkei rikosta olisi tapahtunut. Lisäksi rikollisena kohtelu voi pikemmin tuottaa kuin ehkäistä rikollisuutta, erityisesti nuorten kohdalla. Algoritmin käyttö myös uusintaa esimerkiksi etnisiin suhteisiin liittyviä historiallisia vinoumia: pisteytysjärjestelmä perustuu pidätysten määrään ja pidätysten määrään taas vaikuttaa poliisissa syvällä vaikuttavat rasistiset toimintatavat. (McGrory ja Bedi 2020.)

Toinen esimerkkimme on tapausnäyttöön perustuva politiikka. Näyttöperustaisuus on peräisin lääketieteen kentältä, missä tavoitteena on ollut taata tutkimusten avulla tehokkaimmiksi ja parhaiksi todetut hoitomenetelmät. Sittemmin näyttöpohjaisuus on levinnyt julkishallinnon piiriin. Ideana on, että päättäjille tarjotaan paras käytettävissä oleva tutkittu tieto päätösten tueksi. (Raivio 2014, 15.)

Ajatus intressiristiriidoiksi ymmärretyn politiikan korvaamisesta tutkitusti vaikuttavimmilla tai optimaalisimmilla toimilla edustaa yllä mainittua pyrkimystä "ottaa politiikka pois politiikasta”. Toisin sanoen näyttöpohjaisuus peittää ristiriidat sen sijaan, että ne nousisivat esimerkiksi demokraattisen konfliktin kohteiksi. Episteemisten kulttuurien näkökulmasta on erotettava politiikasta irrotettu tieto (tai pikemmin usko tällaisen tiedon olemassaoloon) ja tiedon rooli poliittisen todellisuuden uusintajana. Kyse on siis toisaalta siitä, minkälaiseen tietoon poliittisissa päätöksissä nojataan, ja toisaalta siitä, uusinnetaanko tieteen avulla kuvattua todellisuutta vai pyritäänkö sitä muuttamaan.

Eri yhteyksissä on pantu merkille, että näyttöön perustuvan politiikan sijaan saadaan usein politiikkaan perustuvaa näyttöä (esim. Strassheim ja Kettunen 2014). Episteemisen kulttuurin näkökulmasta politiikka tulee tässä ymmärtää vallitsevien käytäntöjen jähmeytenä, eikä niinkään valikoidun tiedon etsimisenä yksittäisten intressien tueksi. Hyvä esimerkki on yhteisöveropolitiikan tietopohjan muutos Suomessa (Ylönen ym. 2020). Siinä missä yhteisöveropolitiikassa on aiemmin sovellettu juridisia normeja ja eksplisiittisemmin normatiivista tietoa, nykyisin käsitykset yliajallisista käyttäytymisoletuksista vaikuttavat enemmän politiikan muotoiluun. Kun oletukset reaktioista erilaisiin politiikkatoimiin määräytyvät yliajallisten käyttäytymisoletusten perusteella, politiikan tila kaventuu ${ }^{4}$. Siirtymä toisin sanoen merkitsee sekä lisääntynyttä näytön käyttämistä että politiikan yleistä konservatiivisuutta ja liikkumatilan kaventumista.

Yhteiskunnan institutionaalinen kokonaisuus on poliittisesti muodostettu, joten yhteiskunnasta saatava tieto perustuu menneisyyden valtasuhteiden ja menneisyydessä tehdyn politiikan tuloksiin. Oli politiikan tietopohja mikä tahansa, tietopohjan empiria nousee poliittisesti muokatusta todellisuudesta. Tämä onkin ennalta määrätyn episteemiseen kulttuuriin liittyvien ongelmien ytimessä: kun tulevaisuutta rakennetaan nykyisyydestä saatavan tiedon pohjalta, ja nykyisyys perustuu menneisyydessä tehtyyn politiikkaan, menneisyyden hegemonisia poliittisia ideoita saatetaan tiedostamatta uusintaa. Tällöin kyseessä on sama ilmiö kuin opetettaessa algoritmille todellisuudessa vallitsevia vinoumia: politiikan tietopohja saattaa siirtää vallitsevia vinoumia poliittisiin päätöksiin, ja näin toistaa niitä. 


\section{EPISTEEMISTEN KULTTUURIEN HISTORIALLISET VIRTAUKSET}

Ennalta määrätyn episteeminen kulttuuri on jo pidemmän aikaa vahvistunut yhteiskuntatieteissä, toisilla aloilla enemmän kuin toisilla. Syyt ovat ymmärrettävät: dataa on tarjolla enemmän, sen keräämisen menetelmät ovat kehittyneet, ja se on parempaa ja helpommin saatavilla kuin aikaisemmin. Ennen kaikkea määrällisen datan käyttö parantaa mahdollisuuksia ennakoida tulevaa, tai vähintään saada eksaktimpaa tietoa todennäköisyyksistä.

Kun yhteiskuntatieteilijöiden ihastuminen mahdollisuuksiin saada tarkempia kuvia yhteiskunnasta yhdistyy intresseihin käyttää tätä tietoa, määräytyy tulevaisuus monesti menneisyyttä koskevan tiedon perusteella. Tätä kehitystä osaltaan vahvistaa se, että päätöksenteossa suositaan usein sen kaltaista tietoa, jota on helpompi käyttää menneiden tilojen uudelleentuottamiseen. Nykyisyydelle etäisten institutionaalisten järjestysten tutkiminen ei onnistu samalla tavalla. Kun lisäksi muutokset joka tapauksessa tapahtuvat marginaaleissa, ei nykyisyyttä rikkoville tiedon muodoille ole laajaa kysyntää.

Esimerkiksi uusklassisella taloustieteellä on erityinen asema nyky-yhteiskuntien hallinnassa (ks. esim. Christensen 2017) ja poliittinen päätöksenteko perustuu yleisesti taloustieteen tuottamiin käsitteisiin ja taustaoletuksiin (ks. esim. Birch 2017; Teivainen 2016). Taloustieteen erityinen asema liittyy osaltaan yhteiskuntien ja elämän yleiseen taloudellistumiseen, mutta taloustieteen muoto ja yhteys poliittiseen päätöksentekoon resonoivat myös voimakkaasti episteemisten kulttuurien analyysimme kanssa. Uusklassinen taloustiede on selvimmin historiallis-institutionaalisesti kiinnittymätön ja yliajallisiin käyttäytymisoletuksiin perustuva yhteiskuntatiede. Sen piirissä yleisesti käytettyjen suurten datamassojen yhdistäminen edellä mainittuihin oletuksiin tekee uusklassisesta taloustieteestä malliesimerkin ennaltamäärätyn episteemisestä kulttuurista tiedontuotannon ja politiikan risteyskohdassa.

Tietoa on toki aina käytetty ideologisten tarkoitusperien edistämiseen, eikä itse tiedontuotanto ole koskaan ollut yleisistä sosiologisista vaikuttimista riippumatonta. Kaikki yhteiskuntatiede on myös aina tulkitsevaa: maailmaa ei voi koskaan kuvata jokaisesta näkökulmasta samaan aikaan, minkä lisäksi se on jatkuvassa muutoksessa. Episteemisten kulttuurien historialliset pohjavirtaukset ovat sen sijaan vaikeammin hahmotettava ilmiö. Millä perustein voidaan siis sanoa, että ennalta määrätyn episteemisen kulttuurin vahvistuminen on juuri nykyajalle ominaista?

Vaikka tulevaisuutta on aina rakennettu menneisyyttä koskevan tiedon pohjalta, saatavilla olevan tiedon määrä ja muoto vaikuttavat tulevaisuuden hahmottamisen tapaan ja tästä seuraavaan politiikan liikkumatilaan. Vaikka positivistiset tiedontuotannon muodot saattavatkin vääristää käsitystä todellisuudesta, tulevaisuusskenaariot pohjaavat aiempaa enemmän maailmasta tieteen avulla kerättyyn tietoon. Myös numeroilla oikeuttamisen rooli ja usko numeroihin objektiivisena tietona ovat lisääntyneet merkittävästi (Porter 1995) luoden poliittiseen oikeuttamiseen toisinaan "indikaattorikulttuuriksi" kutsutun ilmiön (Merry 2016). Numeroista ja kvantitatiivisesta datasta on epäilemättä luontevamman tuntuista johtaa jatkuvuuksia, kun käyriä voidaan piirtää samalla trendillä jatkuvana kohti tulevaisuutta. Kun maailman kuvaaminen muuttuu tarkemmaksi tai ainakin kvantifioidummaksi, olemassa oleva todellisuus määrittää voimakkaammin tulevaisuutta. Tämä liittyy niin relevantteina pidettyihin tiedon lajeihin kuin myös siihen, kuinka helppoa tietoa on tuottaa ja hyödyntää. Määrällistä 
dataa pitkälle tulevaisuuteen tähtäävistä koettelemattomista politiikkatoimista ei voi edes olla olemassa.

Kun tietoa on ollut vähemmän ja se on ollut epätarkempaa, on tulkinnalle ja mielikuvitukselle, sekä myös avoimelle politiikalle jäänyt enemmän tilaa. Avoimempi politiikan liikkumatila on tässä ymmärrettävä ennalta määrätyn episteemisen kulttuurin poissaolon aiheuttaman potentiaalin kautta, eikä se tarkoita, että liikkumatila olisi aina realisoitunut muutoksena tai että realisoitunut muutos olisi ollut edistyksellistä. Niin sanottu status quo -vinouma, joka suosii säilyttämistä muutoksen kustannuksella (ks. esim. Samuelson ja Zeckhauser 1988), ei liity suoraan episteemiseen kulttuuriin, vaan on yleisempi inhimillinen taipumus. Status quo -vinouma liitetään usein epärationaaliseen käyttäytymiseen, mutta myös ennalta määrätyn episteemisellä kulttuurilla saattaa olla saman suuntaisia vaikutuksia. Toisaalta tiedon lisääntyminen voi ruokkia kuvittelukykyä ja tulkinnan mahdollisuuksia, mutta ennalta määrätyn episteeminen kulttuuri rajoittaa tiedon muotoja ja roolia yhteiskunnallisessa muutoksessa. Ideaalityyppisen ennalta määrätyn episteemisen kulttuurin vastinparina voidaankin tunnistaa ideaalityyppinen episteeminen kulttuuri, jota voidaan kutsua vaikkapa tulkinnan episteemiseksi kulttuuriksi. Tulkinnan episteemiselle kulttuurille on ominaista, että tietopohja sisältää eksplisiittisesti tieteen ulkopuolelta tulevia oikeutuksia.

\section{POLITIIKAN TUTKIMUS JA DEMOKRAATTISTA TILAA AVAAVA EPISTEEMINEN KULTTUURI}

Olemme yllä esittäneet sekä teoreettisesti että esimerkkien kautta, miten ennalta määrätyn episteemiseksi kulttuuriksi nimeämämme ilmiö vahvistuu nyky-yhteiskuntien tiedollisessa orientaatiossa ja sitä myötä hallinnoinnissa. Yllä olevalla analyysilla on siis kahtalainen tarkoitus. Ensinnäkin katsomme, että on tarpeen tunnistaa (ideaalityyppisiä) episteemisiä kulttuureja ja niiden vaikutuksia. Toiseksi on tarpeen tunnistaa ennalta määrätyn episteeminen kulttuuri demokraattisen politiikan tilan vähintään potentiaalisena kaventajana, olkoonkin että tällöin politiikan tilan kaventuminen liittyy käsityksiin jatkuvuuksista ja mahdollisen rajoista eikä institutionaalisiin rajoitteisiin kuten sanktioihin. Näiden havaintojen pohjalta aukeaa myös laajempia kysymyksiä episteemisten kulttuurien, hallinnoinnin muotojen ja politiikan välisistä suhteista.

Ennalta määrätyn episteeminen kulttuuri (tai mikä tahansa episteeminen kulttuuri) on kuitenkin vaikea tutkimuskohde tarkkarajaisuuden puutteen vuoksi. Ennalta määrätyn episteemisen kulttuurin käsite onkin tarkoitettu ideaalityypiksi. Havainto ennalta määrätyn episteemisen kulttuurin vahvistumisesta ei siis tarkoita pyrkimystä kiistää joitakin välttämättömiä jatkuvuuksia, tai pyrkimystä irrottaa politiikkatoimia kokonaan menneisyyden kokemuksista. Tarkoituksena on pikemmin kiinnittää huomiota käsitykseen menneisyyden ja tulevaisuuden suhteesta ylistaattisena.

Politiikan tutkimuksessa ennalta määrätyn episteeminen kulttuuri tulisi ymmärtää tutkimuskohteena sekä episteemisen kulttuurin itsensä että episteemisen kulttuurin ja hallinnoinnin välisen dynamiikan osalta. Episteeminen kulttuuri vaikuttaa politiikan ja poliittisten mahdollisuuksien hahmotukseen. Jos mennyttä koskevasta tiedosta tulee tulevaisuutta kahlitsevaa, mahdollisten tulevaisuuksien spektri kaventuu. Näin ymmärrettynä demokraattinen liikkumatila on 
kuvittelun tilaa, samaan tapaan kuin Hannah Arendtin mukaan vapaus tarkoittaa mahdollisuutta aloittaa jotain uutta tai tehdä jotain ennalta arvaamatonta (ks. d'Entreves 2019). Poliittiseen tilaan kuuluvat moninaisuus, erot ja erimielisyys sekä julkinen debatti (Mäkinen 2019) menettävät merkitystään jos tiedontuotannon ja -soveltamisen ammattilaiset nähdään parhaina tahoina tekemään ratkaisuja maailmasta siihen asti tehtyjen havaintojen pohjalta.

Potentiaalisen muutoksen tilan (poliittisen liikkumatilan) kaventuessa kaventuvat myös demokraattisen päätöksenteon mahdollisuudet. Demokratian tilaa analysoidaan usein formaalien instituutioiden toimivuuden kautta, sananvapauden kaltaisten perusoikeuksien näkökulmasta ja myös demokraattisen keskustelun laadun näkökulmasta. Analyysi kuitenkin ulottuu harvoin episteemisten kulttuurien vaikutukseen hallinnon ja politiikan saralla. Ennalta määrätyn episteemisessä kulttuurissa hallitseva tieto menneestä rajoittaa teoreettisesti tulevia mahdollisuuksia ja siten vapautta muuttua, tehdä jotain toisin ja aloittaa uutta.

Mitä episteemisen kulttuurin ja hallinnoinnin väliseen dynamiikkaan tulee, olisi pyrittävä hahmottelemaan instituutioihin betonoituneen tiedollisen kulttuurin ja vallitsevan taloudellisen hallinnoinnin yhteyksiä. Episteeminen kulttuuri on vahvasti kytköksissä hallinnollisiin rationaliteetteihin, kuten erityisesti niin sanotussa governmentality-tutkimuksessa on usein tuotu ilmi (Alasuutari ja Qadir 2014; Dean 2010). Myös nykyisen talousjärjestelmän toiminta edellyttää ennalta arvattavuutta: yritykset etsivät pitkiä investointisuojia, ennakoitavuutta ja "poliittisten riskien" hallintaa, ja talouspolitiikan keskeisiä tavoitteita on potentiaalisesti epävakaan talouden edes kohtuullinen vakauttaminen. On syytä sekä paikantaa tämän hallintomuodon ja demokraattisen politiikan välinen jännite, että tutkia miten taloustieteen ylihistorialliset tiedontuotannon muodot tuottavat ja oikeuttavat tämän hallinnointijärjestelmän rationaliteettia.

Kaksi yllä käsiteltyä ideaalityyppistä episteemistä kulttuuria, ennalta määrätyn episteeminen kulttuuri ja tulkinnan episteeminen kulttuuri, eivät myöskään ole ainoita relevantteja episteemisiä kulttuureja. Ensinnäkin vaikka olemme tässä tekstissä tarkoituksella soveltaneet episteemisen kulttuurin käsitettä makrotason ilmiöihin, nyanssoidummille tulkinnan kategorioille voi hyvin olla tarvetta. Todellisessa elämässä episteemisiä kulttuureja on lukuisia, ne toimivat rinnakkain, ja niiden väliset rajat ovat häilyviä. Toiseksi on syytä hahmotella myös muita ideaalityyppisiä episteemisiä kulttuureja yhteiskuntatieteen erilaisten roolien ja mahdollisuuksien hahmottamiseksi. Siksi lopetamme tämän avauksen visioon emansipatorisesta episteemisestä kulttuurista.

Esimerkiksi Jürgen Habermasin mukaan yhteiskuntatieteilijän ei tulisi asettua luonnontieteille ominaiseen objektivoivan tarkastelevaan asemaan, vaan emansipatorinen, alistavista valtasuhteista vapautumaan pyrkivä tiedonintressi on yhteiskuntatieteille ominainen lähestymistapa (ks. Kusch 1986, 166-218). Kuitenkin yksittäisten tutkimuksen emansipatorisen tiedonintressin potentiaalin realisoituminen edellyttäisi laajempaa emansipatorista episteemistä kulttuuria, joka lävistäisi koko tiedon konseptin sen tuotannosta yhteiskunnallisiin käytäntöihin. Nykytutkimuksessa emansipatorista tiedonintressiä edustaa esimerkiksi utopioiden tutkimus ja utopian käyttäminen yhteiskuntatieteellisenä metodina (ks. esim. Eskelinen 2020; Nuorisotutkimusseura 2020; Lakkala 2017). Poliittista mielikuvitusta tutkitaan ja pyritään edistämään Suomessa esimerkiksi Turun yliopiston POLIMA-hankkeessa (Hyytiäinen 2020).

Emansipatorista episteemistä kulttuuria voidaankin tulkita yhtenä ideaalityyppinä, joka osoittaa suuntaa demokraattista tilaa avaavalle tietosuhteelle. Myös tällaisen ideaalityypin 
tunnistamisen ja sen tavoittelun tulisi kuulua politiikan tutkimuksen tavoitteisiin. Erityisesti demokraattisen politiikan tilan laajentamisen näkökulmasta on tärkeää laajentaa tietokäsitystä niin, että se sisältää välittömän empirian ohella lähtökohdan siitä, että yhteiskunnallinen todellisuus voisi olla ratkaisevasti nykyisestä poikkeava. Demokratiaa laajentavan yhteiskuntatieteen yksi tehtävistä on tuottaa demokraattisen keskustelun pohjaksi näkymiä radikaalisti toisenlaisista yhteiskunnista.

\section{VIITTEET}

1. Cetina erottelee tietokulttuurit (knowledge cultures) ja episteemiset kulttuurit (epistemic cultures). Emme tässä artikkelissa seuraa tuota erottelua, vaan viittaamme episteemisen kulttuurin käsitteellä yleisesti tietämisen tapoihin, käytänteisiin ja rationaliteetteihin.

2. Monimutkaisuus seuraa siitä, että ennalta määrätyn episteemisen kulttuurin piirissä tuotettu tieto sisältää myös esimerkiksi aksiomaattisia päätelmiä, jotka eivät liity suoraan menneisyyttä koskeviin aistikokemuksiin. Tulevaisuuden muodostusta tapahtuu myös jäykkien toivottavuus- ja mahdollisuusraamien ulkopuolella.

3. Keinoälyä koskevassa keskustelussa vinoumilla viitataan epätoivottujen seurausten lisäksi myös epätarkkaan tai virheelliseen informaatioon. Näistä ensimmäinen liittyy selvemmmin ennalta määrätyn episteemiseen kulttuuriin, eikä näitä mekanismeja voi aina täysin suoraviivaisesti erottaa toisistaan. Toisinaan yksipuolinen tai epätarkka tieto voi aiheuttaa ongelmallisia lopputulemia, esimerkiksi alistavia valtarakenteita. Toisinaan ongelmallisia rakenteita ja toimintamalleja sisältävää maailmaa toisinnetaan sitä tarkasti kuvaavan tiedon avulla.

4. On kuitenkin syytä selventää, että tässä tapauksessa käyttäytymisoletukset on johdettu ortodoksisen taloustieteen teoreettis-metodologisesti kapealla apparaatilla, eli kyse on taas ainakin osittain tiedon laatuun liittyvistä vinoumista. Toisaalta, vaikka kyseessä olevat oletukset ottavat käyttäytymisen ja sen vaikuttimien moninaisuutta kapeasti huomioon, ovat nämä käyttäytymispiirteet kapitalististen instituutioiden todellisuudessa keskimäärin vahvoja. Tällöin kyse on myös sosiaalisen todellisuuden toisintamisesta.

\section{LÄHTEET}

Abulof, Uriel ja Kornprobst, Markus. 2017. Introduction: The Politics of Public Justification. Contemporary Politics 23:1, 1-18.

Akyüz, Yilmaz. 2007. Global Rules and Markets: Constraints over Policy Autonomy in Developing Countries. TWN Global Economy Series No. 10. Penang: Third World Network.

Alasuutari, Pertti ja Qadir, Ali. 2014. Epistemic Governance: An Approach to the Politics of Policymaking. European Journal of Cultural and Political Sociology 1:1, 67-84.

Birch, Kean. 2017. Techno-economic assumptions. Science as Culture 26:4, 433-444.

Campbell, John L. 2002. Ideas, politics, and public policy. Annual Review of Sociology 28:1, 21-38 
Cetina, Karin Knorr. 1999. Epistemic Cultures: How the sciences make knowledge. Massachusetts ja Lontoo: Harvard University Press.

Chambers, Simone. 2010. Theories of Political Justification. Philosophy Compass 5:11, 893-903.

Christensen, Johan. 2017. The power of economists within the state. Stanford, California: Stanford University Press.

Cooley, Mike. 1995. The myth of the moral neutrality of technology. AI \& Society 9:1, 10-17. https://doi.org/10.1007/BF01174475

Dean, Mitchell. 2010. Governmentality: Power and Rule in Modern Society. 2nd ed. Thousand Oaks, CA: SAGE Publications.

d'Entreves, Maurizio Passerin. 2019. Hannah Arendt. Teoksessa Edward N. Zalta (toim.), The Stanford Encyclopedia of Philosophy. https://plato.stanford.edu/archives/fall2019/entries/arendt/. Viitattu 23.6.2021.

Eskelinen, Teppo. 2020. The revival of political imagination: utopia as methodology. Lontoo: Zed Books.

Eskelinen, Teppo ja Sorsa, Ville-Pekka. 2013. The production of institutional facts in economic discourse. World political science review 9:1, 1-30.

Fricker, Miranda. 2007. Epistemic injustice: power and the ethics of knowing. Oxford: Oxford University press.

Föllesdal, Andreas ja Hix, Simon. 2006. Why there is a democratic deficit in the EU? A response to Majone and Moravcsik. Journal of Common Market Studies 44:3, 533-562.

Gill, Stephen. 2002. Constitutionalizing inequality and the clash of globalizations. International Studies Review 4:3, 47-65.

Hill, Michael ja Varone, Frederic. 2021. The public policy process. 8th edition. Oxon: Routledge.

Hyytiäinen, Erja. 2020. Tutkijat haluavat herättää poliittisen mielikuvituksen eloon. Turun yliopisto. https://www.utu.fi/fi/ajankohtaista/uutinen/tutkijat-haluavat-herattaa-poliittisen-mielikuvitukseneloon. Viitattu 4.5.2021.

Kastenhofer, Karen. 2007. Converging epistemic cultures?: A discussion drawing on empirical findings. Innovation 20:4, 359-373. https://doi.org/10.1080/13511610701767908

Kentikelenis, Alexander, Stubbs, Thomas ja King, Lawrence. 2016. IMF conditionality and development policy space, 1985-2014. Review of International Political Economy 23:4, 543-582.

Kusch, Martin. 1986. Ymmärtämisen haaste. Oulu: Kustannusosakeyhtiö Pohjoinen.

Lakkala, Keijo. 2017. Utopia yhteiskunnallisen mielikuvituksen metodologiana. Futura 36:1 14-21.

McGrory, Kathleen ja Bedi, Neil. 2020. Targeted. Tampa Bay Times. https://projects.tampabay.com/ projects/2020/investigations/police-pasco-sheriff-targeted/intelligence-led-policing. Viitattu 4.5.2021.

Merry, Sally E. 2016. The seductions of quantification. Chicago ja Lontoo: The University of Chicago Press.

Mäkinen, Katja. 2019. Taidetta ja kohtaamisia: Osallistujien kokemuksia EU:n osallistavassa hallinnassa. Politiikka 61:3, 223-246.

Nuorisotutkimusseura. 2020. NUTOPIA - tutkimushanke nuorten utopioista ilmastonmuutoksen aikakaudella. https://www.nuorisotutkimusseura.fi/hankkeet/nutopia. Viitattu 4.5.2021.

Pazzanese, Christina. 2020. Great promise but potential for peril. The Harvard Gazette. https://news. harvard.edu/gazette/story/2020/10/ethical-concerns-mount-as-ai-takes-bigger-decision-makingrole/. Viitattu 4.5.2021. 
Porter, Theodore. 1995. Trust in numbers. The pursuit of objectivity in science and public life. Princeton: Princeton University press.

Raivio, Kari. 2014. Näyttöön perustuva päätöksenteko: suomalainen neuvonantojärjestelmä. Valtioneuvoston kanslian raporttisarja 3/2014. https://julkaisut.valtioneuvosto.fi/bitstream/handle/10024/79693/R0314_N\%c3\%a4ytt\%c3\%b6\%c3\%b6n_net.pdf?sequence=1\&isAllowed=y. Viitattu 19.8.2021.

Reddy, Sanjay. 1996. Claims to expert knowledge and the subversion of democracy: the triumph of risk over uncertainty. Economy and society 25:2, 222-254.

Reho, Federico. 2014. European Union after the sovereign debt crisis: A post-democratic polity? The Public Sphere: Journal of Public Policy 2:1, 83-99.

Samuelson, William ja Zeckhauser, Richard. 1988. Status quo bias in decision making. Journal of Risk and Uncertainty 1, 7-59. https://doi-org.libproxy.helsinki.fi/10.1007/BF00055564

Schneiderman, David. 2000. Investment rules and the new constitutionalism. Law \& Social Inquiry $25: 3,757-87$.

Strassheim, Holger ja Kettunen, Pekka. 2014. When does evidence-based policy turn into policy-based evidence? Configurations, contexts and mechanisms. Evidence \& Policy: A Journal of Research, Debate and Practice 10:2, 259-277.

Teivainen, Teivo. 2016. Ekonomismi ja demokratian tulevaisuus. Teoksessa Sari Kivistö, Sami Pihlström ja Mikko Tolonen (toim.), Talous ja moraali. Helsinki: Gaudeamus.

Ylönen, Matti, Jaakkola, Jussi, Saari, Leevi ja Hiilamo, Heikki. 2020. Näyttöperusteisuus ja yritysten verotus: ekonomismin nousu suomalaisen yhteisöveropolitiikan tiedontuotannossa. Poliittinen Talous 8:1.

Ylöstalo, Hanna. 2020. Asiantuntijavalta politiikassa. Politiikasta. https://politiikasta.fi/asiantuntijavalta-politiikassa/. Viitattu 4.5.2021.

Zajko, Mike. 2021. Conservative AI and social inequality: conceptualizing alternatives to bias through social theory. AI \& Society. https://doi.org/10.1007/s00146-021-01153-9

\title{
KIRJOITTAJATIEDOT
}

\author{
PAULI HUOTARI \\ VTM, väitöskirjatutkija \\ Yleinen valtio-oppi, valtiotieteellinen tiedekunta \\ Helsingin yliopisto \\ pauli.huotari@helsinki.fi
}

\section{TEPPO ESKELINEN}

Yhteiskuntapolitiikan dosentti, yliopistonlehtori

Yhteiskuntatieteet, yhteiskuntatieteiden laitos

Itä-Suomen yliopisto

teppo.eskelinen@uef. 